\title{
The influence of PSA's likeability on children's intentions to eat healthy food
}

\author{
Valentina Nicolini ${ }^{1}$ (D) Fabio Cassia $^{2}$ (D)
}

Received: 19 August 2020 / Accepted: 15 April 2021 / Published online: 27 May 2021

(C) The Author(s) 2021

\begin{abstract}
This paper suggests a model that considers the effects of the children's attitude toward Public Service Announcements-PSAs (measured through the likeability of PSAs) on their behavioural intention to eat fruits and vegetables. The suggested model was tested through an empirical analysis conducted with children aged 8 to 11 and the data were analysed through partial least squares - structural equation modeling (PLS-SEM) multigroup analysis. The findings indicate that the positive emotions PSAs generate and PSA credibility mediate the effects of the children's perceived likeability of PSAs on their behavioural intention to eat fruits and vegetables. Overall, understanding the connections between PSA likeability, positive emotions, PSA credibility and behavioural intentions can facilitate the development of further social advertisements aimed at children covering healthy eating. Therefore, the findings of this study are relevant for non-profit organizations, government institutions and advertisers interested in creating effective social messages aimed at children.
\end{abstract}

Keywords Advertising · Children · Public service announcements · Healthy food · Nonprofit marketing

\section{Introduction}

Childhood obesity is one of the most alarming global problem of our century. The percentage of obesity among children and youth has more than tripled in many European countries and in the United States since the 1970s (Center for Disease Control \& Prevention, 2017; European Commission, 2014). For example, in the European

Valentina Nicolini

valentina.nicolini@univr.it

Fabio Cassia

fabio.cassia@univr.it

1 University of Verona, Via San Francesco 22, 37129 Verona, Italy

2 University of Verona, Department of Business Administration via Cantarane, 24, 37129 Verona, Italy 
Union (EU) area, around 1 in 3 children aged 6-9 years were overweight or obese in 2010 and in the United States, 12.3 million children and adolescents were obese in 2011 (European Commission, 2014; National Collaborative on Childhood Obesity Research, 2011). The Italian "Istituto Superiore di Sanità" reported that globally, about 50 million girls and 74 million of boys aged 5-19 years were obese (Istituto Superiore di Sanità, 2020).

Specifically, it was estimated that around 1 in 4 minors were overweight or obese in Italy and in particular $21 \%$ of children at the primary school were overweight and 9\% were obese (Bagnato et al., 2020). Italy has participated in the "OPEN, Obesity Policy Engagement Network" recently and the study group called "Obesità" of the Società Italiana di Endocrinologia e Diabetologia Pediatrica (SIEDP) has written a "Percorso Diagnostico Terapeutico Assistenziale-Diagnostic Therapeutic Assistance Path" (PDTA) in order to promote correct diet behaviours in families with children and at schools (Bagnato et al., 2020). In addition, the Italian "Centro Nazionale per la Prevenzione delle Malattie e la Promozione della Salute" (CNaPPS) was designated as collaborator centre of the World Health Organization (WHO) for the control of childhood obesity in 2020 (Istituto Superiore di Sanità, 2020).

Certain studies (Center for Disease Control \& Prevention, 2017; European Commission, 2014; Lobstein et al., 2004; Ogden et al., 2015), have revealed that childhood obesity is associated with many health risks such as asthma, sleep apnea, bone and joint problems, type 2 diabetes, hyperinsulinemia, poor glucose tolerance, hypertension, and risk factors for heart disease. In addition, children who are obese or overweight before puberty will probably continue to be so during adulthood (WHO, 2016).

Further, obesity influences the social and emotional health of a child. The selfesteem of obese children is often low, and these children are teased and bullied more by peers about their body shape. Consequently, they are more likely to suffer from depression and isolation than other children (Center for Disease Control \& Prevention, 2017; Lobstein et al., 2004).

Studies regarding parents' child-feeding practices, children's food and beverage preferences and considering children as food consumers received more attention over the past few years (Ardizzone et al., 2019; Pettigrew \& Pescud, 2012). A multiplicity of factors like eating away from home, sedentariness, access to ready-to-eat meals and parents' habits affects the eating behaviours of youth (Eck et al., 2019), but research (Batada \& Wootan, 2007; Hingle \& Kunkel, 2012; Lioutas \& Tzimitra-Kalogianni, 2015; National Collaborative on Childhood Obesity Research, 2011) indicates that food advertisements and food marketing are one of the predominant causes of the unhealthy diet of children. In fact, food advertisements and marketing directed toward children promotes energy-dense and nutrient-poor diets and influence their food preferences and food purchase requests (Cairns et al., 2013; Dixon et al., 2017; Persson et al., 2012).

Children watch many food commercials on television, and it was estimated that more than US\$ 10 billion per year is spent on all types of food and beverage marketing aimed at children and youth (National Collaborative on Childhood Obesity Research, 2011). The broadcast of public service announcements (PSAs) that encourage children to eat healthy food are fewer than common commercials about sugary cereals, sugar sweetened beverages, fast food meals, pastries and other 
food of poor nutritional quality (Batada \& Wootan, 2007; Gantz et al., 2008). PSAs are a type of messages that are important for public education and are designed to raise awareness, change attitudes, and modify detrimental behaviours about many social issues.

Hence, consistent with prior research, terms such as PSAs, advertisements and commercials are used in this study to convey different shades of meaning. Advertisements are considered as any type of message (commercial or public) delivered through a mass medium (printed materials, e-mail, telephone, radio, television and Internet, etc.) to a target audience. Commercials refer to a category of advertisements paid by companies to promote their services or products and broadcasted on television or radio. Finally, public service announcements (PSAs) are messages of nonprofit organizations or government agencies that inform and try to change attitude/behaviour about important issues.

Public communication campaigns are one of the instruments available in social marketing. As Kubacki et al. (2015) stated, social marketing can be considered an effective approach to increase physical activity and healthy eating in children.

Atkin and Rice (2013, pp. 1-2) defined public communication campaigns as a

"purposive attempts to inform, persuade, or motivate behaviour changes in a relatively well-defined and large audience, generally for noncommercial benefits to the individuals and/or society at large, within a given time period, by means of organized communication activities involving mass and online/interactive media, and often complemented by interpersonal support".

In general, PSAs rely on donated media and if PSAs are properly designed and receive sufficient airtime to address their target audience, these can have a significant effect on changing or preventing unhealthy habits and on encouraging the adoption of good practices (Gantz et al., 2008).

Although an extensive body of research (Boyland \& Halford, 2013; Buijzen et al., 2008; Castonguay et al., 2013; Hingle \& Kunkel, 2012; Kelly et al., 2008; Pettigrew et al., 2013) has focused on the topic of children and food commercials and the consequent negative effects on children's diet, little is known about the effectiveness of PSAs that promote healthy food to children.

There is an impressive extensive literature (Charry, 2014; Ferguson et al., 2012; Folkvord et al., 2020; Hampson et al., 2009; Lencucha et al., 2018; Raine, 2005; Xie et al., 2016) about promotional activities research related to healthy food but almost all of these studies have focused on adults as target. Only one of the aforementioned studies (Charry, 2014) specifically considers children. Nevertheless, the above-mentioned study evaluated the use of product placement that differs from the use of classic advertisements.

In addition, this study's purpose was to find results relevant for non-profit organizations, government institutions and advertisers interested in creating effective social marketing interventions. Hence, we examined relations and variables related to PSAs differently from the vast majority of studies that focused only on the effects of commercial advertising on children. Therefore, the paper 
tries to explain that the gap in existing literature is the association between 1) the use of PSAs and 2) their being addressed to children as their target audience.

To fill the gap in the literature, this study suggests a model that draws on Eagly and Chaiken's (2007) theory of three types of evaluative responses elicited by an object (affective, cognitive and behavioural) and considers the effects of the children's attitude toward PSAs (measured through the likeability of PSAs) on their behavioural intention to eat fruits and vegetables. In the model developed in this study, the positive emotions PSAs generate and PSA credibility mediate the effects of the children's perceived likeability of PSAs on their behavioural intention to eat fruits and vegetables. In addition, it is hypothesized that children's perceived likeability of PSAs has additional direct effects on such behavioural intention. The suggested model was tested through an empirical analysis conducted in Italy with children aged 8 to 11 .

This study contributes to both theory and practice. In relation to theory, few studies have examined relations and variables related to PSAs that are useful in influencing children's behavioural intention to adopt good practices. Most studies have focused only on the effects of commercial advertising on children and/or adults. In relation to practical implications, findings are relevant for non-profit organizations, government institutions and advertisers interested in creating effective social messages aimed at children. A well-designed PSA can help children to choose healthy lifestyle habits in early childhood.

\section{Theoretical background}

The literature about children and commercial advertising has explored a great variety of topics including the influence of children on family purchases after exposure to commercials and the parent-child conflict (Buijzen \& Valkenburg, 2003; Ebster et al., 2009; Page et al., 2018; Valkenburg, 2004), content analyses of television advertisements and persuasive marketing techniques to promote products to children (Hebden et al., 2011; Jenkin et al., 2014; Kim et al., 2016; Puggelli \& Bertolotti, 2014), children's comprehension of advertising and, in particular, their ability to understand the persuasive intent of commercial advertising (Carter et al., 2011; Chan, 2000; Oates et al., 2002), children's ability to recognize commercial advertisements on television and on the Internet (An et al., 2014; Blades et al., 2013; Carter et al., 2011) and finally, the influence of advertising on children's brand awareness and brand preferences (Boyland \& Halford, 2013; Pecheux \& Derbaix, 1999; Valkenburg \& Buijzen, 2005).

Most of the above-mentioned studies focused on the energy-dense, nutrientpoor food and beverages commercials aimed at children, forgetting the key role that PSAs can have in influencing children's healthy food choices. The general literature on PSAs or social marketing interventions targeted at minors is limited (Hota et al., 2010; Kubacki et al., 2015).

Therefore, this study addresses the gap in existing literature regarding the association between the use of PSAs and their being addressed to children as their target audience. 
In the research field concerning the measurement of the effectiveness of advertisements (Kim \& Cappella, 2019), the construct of attitude toward advertising has gained a primary role. Attitude is defined as "a psychological tendency that is expressed by evaluating a particular entity with some degree of favour or disfavour" (Eagly \& Chaiken, 2007, p. 598). MacKenzie and Lutz (1989) applied this definition to the advertising context and they suggested that we can consider attitude toward advertising the consumers' favourable or unfavourable response to a specific advertising stimulus during a particular exposure occasion.

Unfortunately, most studies have mainly measured attitude toward advertising among adults and only a few recent studies have analysed the children's attitude toward advertising (Chan \& McNeal, 2004; D'Alessio et al., 2009; Derbaix \& Pecheux, 2003; Ghani \& Zain, 2004; Gulla \& Purohit, 2013; Nicolini et al., 2017; Priya et al., 2010).

In this study, we suggest a research model (Fig. 1) that draws on Eagly and Chaiken's (2007) theory of the three types of evaluative responses elicited by an attitude object (in this case, the advertisement): cognitive, affective, and behavioural (Eagly \& Chaiken, 2007). The first concerns associations between an attitude object and the attributes that a person ascribe to it (i.e., perceptions, concepts and beliefs). The affective response includes emotions, feelings and physiological responses to the attitude object. The behavioural response refers to actions and intentions to act toward the attitude object. The simultaneous presence of all three responses is not essential, because an attitude can be expressed through one response or a mix of these (Eagly \& Chaiken, 2007).

Since attitude toward advertising is a favourable or unfavourable response to a particular advertisement, it is possible to measure it using the concept of advertising likeability. As Smit et al. (2006) underlined, the concepts of advertising likeability and attitude toward advertising are used interchangeably in the literature. Advertising likeability is utilized as a predictor of advertising effectiveness, as a diagnostic tool, and as a gatekeeper for further processing (Leather et al., 1994).

Similarly, advertising likeability can explain cognitive, affective and behavioural processing of advertisements (Smit et al., 2006). First, likeable advertisements can influence consumer judgment of the message and memory. In this way, recalling the information and features about the product or service advertised become simpler.

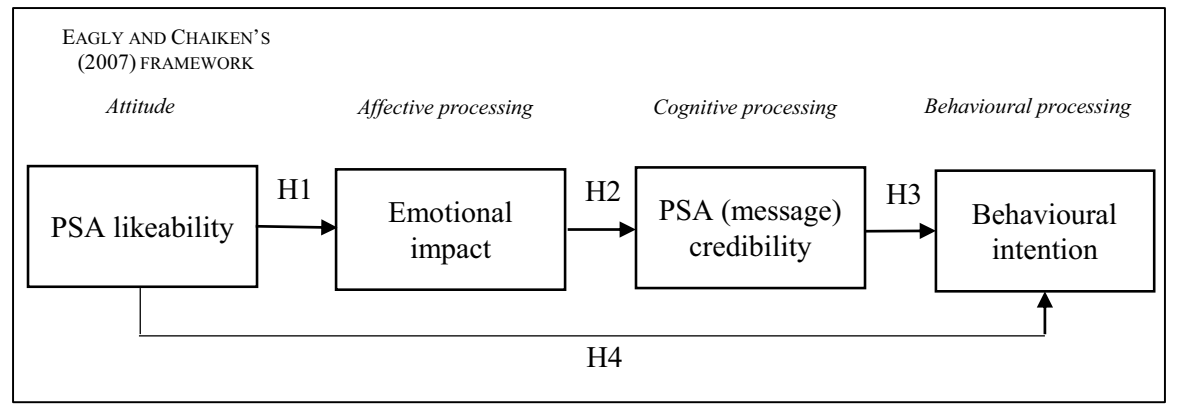

Fig. 1 The research model 
Second, a well-liked advertisement can elicit positive emotions in the viewer. Finally, liking an advertisement can be related to liking a brand and, consequently, to purchase intention.

As underlined above, the attitude toward advertising and the advertising likeability explains affective and cognitive reactions. Two constructs related to attitude and likeability that are useful to increase advertising effectiveness are the emotional impact generated by an advertisement and the perceived advertisement credibility. The emotional impact belongs to the affective sphere, and credibility to the cognitive sphere.

Bagozzi et al. (1999, p. 184) defined emotions as "mental states of readiness that arise from appraisals of events or one's own thoughts". Although the term appraisal can mean evaluation, we have to consider that it covers all types of impressions and perceptions (Mulligan \& Scherer, 2012). Further, the appraisal can be conscious or unconscious, depending on the person and the eliciting conditions (Bagozzi et al., 1999). Emotional appeals are often used in advertising and the degree to which individuals experience emotions is measured in advertising contexts (Erevelles, 1998).

In general, children's reactions to commercials is different from that of adults (Derbaix \& Bree, 1997). If children find the advertisement's message interesting (or uninteresting), their response is primarily an emotional one (Derbaix \& Bree, 1997). Emotional and rational components play a significant role in children's preference for an advertisement but the emotional component appears to be preeminent (Nicolini et al., 2017). Conversely, adults often watch a commercial to search for information and their reactions (i.e., cognitive or emotional) depend on multiple factors such as their age, the product advertised (i.e., product vs service), and their interests (Ruiz \& Sicilia, 2004; Yoo \& MacInnis, 2005).

As Derbaix and Bree (1997, p. 208) stated, "What children seem to look for in an advertisement is a state of mind where special elements can be strong enough to generate a feeling of pleasure". Children tend to favour aspects related to enjoyment and entertainment such as humour, jingles, adventure, fantasy, fun and cartoon characters (Boyland et al., 2012; Buijzen \& Valkenburg, 2002; Hebden et al., 2011; Lawlor, 2009; Page \& Brewster, 2007; Rose et al., 2012). The same aspects were observed in the PSAs context (Hota et al., 2010; Nicolini et al., 2017). In addition, a study (Roozen, 2013) on young students highlighted that the emotional response to advertisements is high particularly for not-for-profit brands.

In the related literature about attitude and advertising, the idea of credibility has been conceptualized and measured in many forms (Appelman \& Sundar, 2016; Porter et al.,, 2015; Soh et al., 2009; Verma, 2014): source credibility (i.e., the credibility of endorsers, advertisers and companies), message credibility (i.e., the truthfulness of advertisement claims), media credibility (i.e., the credibility of the channel used to convey advertisements) and advertising credibility (i.e., the credibility of advertising in general).

This study focused on the content message credibility perceived by children because the aim of the two PSAs used in the study was to encourage children to eat healthy food and consequently it was important to understand if children perceived the message and the story as truthful and believable. This choice is also consistent 
with the empirical analysis presented in this paper, in which the script of the PSAs being examine made it not possible to use other forms of credibility. For example, there were not famous endorsers or brand (source credibility) and it was not possible to consider the channel (media credibility) because PSAs were shown through researchers' laptops.

Appelman and Sundar (2016, p. 63) defined message credibility related to a nonspecific context as "an individual's judgment of the veracity of the content of communication". The definition of advertisement credibility is similar. It is defined as "the extent to which the consumer perceives claims made about the brand in the ad to be truthful and believable" (MacKenzie \& Lutz, 1989, p. 51).

Obermiller and Spangenberg (1998, p. 160) approached the concept of advertisement credibility from an opposite direction. They used the construct of scepticism toward advertising, which is defined as "the tendency toward disbelief of advertising claims". Soh et al. (2009) stated that there are many similarities between the two constructs and in this way, it is possible to consider scepticism toward advertising an additional instrument to measure credibility from another viewpoint.

Chan and McNeal (2004) highlighted the lack of research that investigates how children make judgments about the degree of truthfulness of commercials. The credibility aspect of advertisements is an important factor to measure the influence of advertisements on children (Gulla \& Purohit, 2013). In general, children tend to believe advertisements because for them, advertisements represent a source of information (Gulla \& Purohit, 2013; Priya et al., 2010). However, advertisement credibility perceived by children depends on their age (Chan \& McNeal, 2002; Priya et al., 2010) and sometimes on the context in which they live (i.e., rural or urban) (Chan, 2014). As children move into adolescence, they cease believing that advertisements are always true and their scepticism toward advertisements increases (Chan \& McNeal, 2002, 2004; Freeman \& Shapiro, 2014). Chan (2001) found that the judgment by older children about advertisement credibility depends more on personal experience, while that of younger children, on other's comments.

If children become more sceptical toward advertisements and aware of the marketing tactics used in commercials, they are more likely to avoid advertisements (Freeman \& Shapiro, 2014). Therefore, advertisements for children should appear credible and quite realistic, rather than merely entertain (Priya et al., 2010).

Few studies have focused on the perceived credibility of social advertisements (Thakor \& Goneau-Lessard, 2009). Thakor and Goneau-Lessard (2009) developed a scale to measure social advertising scepticism among adolescents and found that adolescents who do not believe social advertisements regard them more negatively.

\section{Model and hypotheses}

Based on Eagly and Chaiken's (2007) theory of the three types of evaluative responses and on the arguments presented above, it is suggested that advertising likeability has effects on children's behavioural intention to eat fruits and vegetables. The model encompasses the indirect (through the positive emotions and credibility 
elicited by PSAs) and direct effects of perceived likeability of PSAs on children's behavioural intention to eat fruits and vegetables.

\subsection{Indirect effects}

As stated earlier, attitude toward advertisements and advertising likeability can be explained in terms of three types of responses, one of which is the affective response (Eagly \& Chaiken, 2007; Smit et al., 2006). Therefore, a well-liked advertisement can elicit positive emotions in the viewer (Smit et al., 2006). Children's response toward an advertisement is mainly related to the affective dimension and the characteristics and benefits of the product advertised are often considered of secondary importance by them (Derbaix \& Bree, 1997). When they find the message interesting, they primarily have an emotional response (Derbaix \& Bree, 1997). (Lioutas \& Tzimitra-Kalogianni, 2015) explained that food advertising affects children by generating expectations, feelings, emotions, and positive moods. Therefore, we suggest the following hypotheses:

H1. Children's perceived likeability of PSAs (or positive attitude toward PSAs) has a positive effect on their emotional response to PSAs.

Bagozzi et al. (1999, p. 195) stated that “A person's emotional state can influence various aspects of information processing including encoding and retrieval of information, different strategies used to process information, evaluations and judgments, and creative thinking". In particular, individuals in a positive affective state evaluate stimuli more positively because they base their evaluation on their affective reactions to the object (Bagozzi et al., 1999). Previous studies (Chan, 2001; Chan \& McNeal, 2004) have suggested that children who enjoy commercials and have positive emotions toward commercials perceive these to be mostly true (and vice versa). Drawing on this reasoning, the following hypothesis is proposed:

H2. Children's positive emotional response to PSAs has a positive effect on the perceived credibility of PSAs.

There is extensive evidence (Chan \& Zhang, 2019; Goldsmith et al., 2000; Lafferty et al., 2002; Ohanian, 1991) that the credibility of companies and endorsers influence adults' purchase intention. Notably, no studies investigate how children judge the credibility of commercials and how advertisement credibility influences their behaviour (Chan $\&$ McNeal, 2004). Children tend to believe advertisements because to them, advertisements represent a source of information (Gulla \& Purohit, 2013; Priya et al., 2010). Consequently, it is possible that the credibility of an advertisement perceived by children can have an impact on their behaviour. Priya et al. (2010) confirmed that the credibility aspect of the advertisement has an impact on buying behaviour of certain age groups of children. Following this reasoning, we suggest the following hypothesis: 
H3. The children's perceived credibility of PSAs has a positive effect on their behavioural intention to eat fruits and vegetables.

\subsection{Direct effects}

There is extensive evidence that children's positive attitudes toward advertisements (or advertising likeability) have a direct influence on their purchase intention (D’Alessio et al., 2009; Pecheux \& Derbaix, 2002; Phelps \& Hoy, 1996). Similar to D'Alessio et al. (2009, p. 412), we considered behavioural intention as "the subjective perception of the persuasive power of TV advertising, the perceived evaluation of the effect on desire for the advertised products and the effect on their request to parents to buy these products", but we adapted this definition to social messages.

Rossiter (1979) stated that commercials create in children a desire for a product that can translate into actual and intended behaviour. Children with a positive attitude toward an advertisement like and appreciate it, and they request the products that they have seen on the advertisement (Ghani \& Zain, 2004). Hota et al., (2010) hypothesized that the same relationship between attitude and behaviour could exist in the context of PSAs. Hence, we posit the following:

H4. Children's perceived likeability of PSAs (or attitude toward PSAs) has a positive effect on their behavioural intention to eat fruits and vegetables.

\section{Method}

This study has a cross-sectional design and was conducted with children aged between 8 and 11 years. The questionnaire was adapted to social advertisements context from Derbaix and Pecheux (2003), Baumgartner and Laghi (2012); Lioutas and Tzimitra-Kalogianni (2015).

A four-point Likert scales (not at all $=1$, a little $=2$, a lot $=3$, very much $=4$ ) was used to avoid the tendency of children to mark the neutral mid-point (Hota et al., 2010).

First, items were tested with 11 children to ensure that the questions were understandable, and to check whether there was any ambiguity in the sentences. Second, consent was obtained from the parents of 143 children $(\mathrm{F}=72 ; \mathrm{M}=71)$. Finally, the questionnaire was administered to these children during school hours at a primary school in Italy.

The children filled out the questionnaire after viewing a PSA. With the intent of ensuring higher external validity of the results, two PSAs were used in the experiment and children were randomly assigned to one of them. The advertisements showed to the children were "Frutta nelle scuole" (Ad \#1) created by the Italian Ministry of Agricultural, Food and Forestry Policies and "The Greatest Action Movie Ever" (Ad \#2) created by the American Advertising Council. "The Greatest Action Movie Ever" advertisement was professionally dubbed into Italian. 
The Italian PSA is a fantasy stop-motion animation. The main characters are personified fruits and vegetables. This advertisement encourages children to eat healthy food by comparing and presenting fruits and vegetables as an interesting subject that they may wish to learn more about at school. It states that fruits and vegetables will also be appreciated by parents and can be shared with them. The American PSA is filmed as a movie trailer. The main characters are a group of real children, whose superpowers are created using special effects and a cartoon monster. This advertisement shows children that they can acquire many superpowers by eating fruits and vegetables, so much so that they would even be able to defeat a monster.

A total number of 66 children watched Ad \#1 and 67 children watched Ad \#2. The two advertisements were selected based on two experts' evaluations of the cognitive efforts required to process them. In fact, previous research suggests that consumers -and children, as well (Nicolini et al., 2017) -may process the information contained in an advertising message through different routes depending on the required cognitive efforts (Petty et al., 1983). As expected, the manipulation check confirmed that "Frutta nelle scuole" required less effort to be understood than "The Greatest Action Movie Ever" $(X=3.19$ versus X=3.44; $\mathrm{t}(142)=2.08 ; p<0.05)$.

Data were analysed through partial least squares - structural equation modeling (PLS-SEM) multigroup analysis. PLS-SEM is primarily used to develop theories when there is little a priori knowledge on the topic and when the emphasis is on more exploration than confirmation (Hair et al., 2017, 2019). Moreover, PLS-SEM can be applied when the sample size is small and data are nonnormally distributed. In detail, PLS-SEM requires the sample size to be at least 10 times the largest number of paths in the structural model directed at a specific construct (Hair et al., 2020). In this study, the largest number of structural paths pointing at a particular construct is two, meaning that the sample size for each group should be at least equal to 20 . The analysis was conducted using the software SmartPLS 3 (Ringle et al., 2015). Age was also added as a control variable.

\section{Results}

Before assessing the structural model, the measurement models were evaluated. As all constructs were reflectively measured, we analysed factor loadings, internal consistency reliability, convergent validity and discriminant validity for each of the two groups (i.e., children watching ad \#1 and ad \#2, respectively) (Hair et al., 2019). All loadings were above 0.70 , except for two loadings (Table 1). The average variance extracted (AVE) for each latent construct was greater than 0.50 and the composite reliability $(\mathrm{CR})$ was beyond 0.70 . Thus, both reliability and convergent validity were attained (Fornell \& Larcker, 1981). After that, we assessed that the discriminant validity had been met, meaning that each construct is distinct from the other constructs. For this purpose, we first applied Fornell-Larcker (1981) criterion by assessing that for each construct the square root of the AVE was greater than its maximum and average correlation with other constructs (Table 2). Then, we assessed the heterotrait-monotrait ratio (HTMT) of the correlations. The analysis indicated that the HTMT values for all pairs of constructs were well below the threshold of 


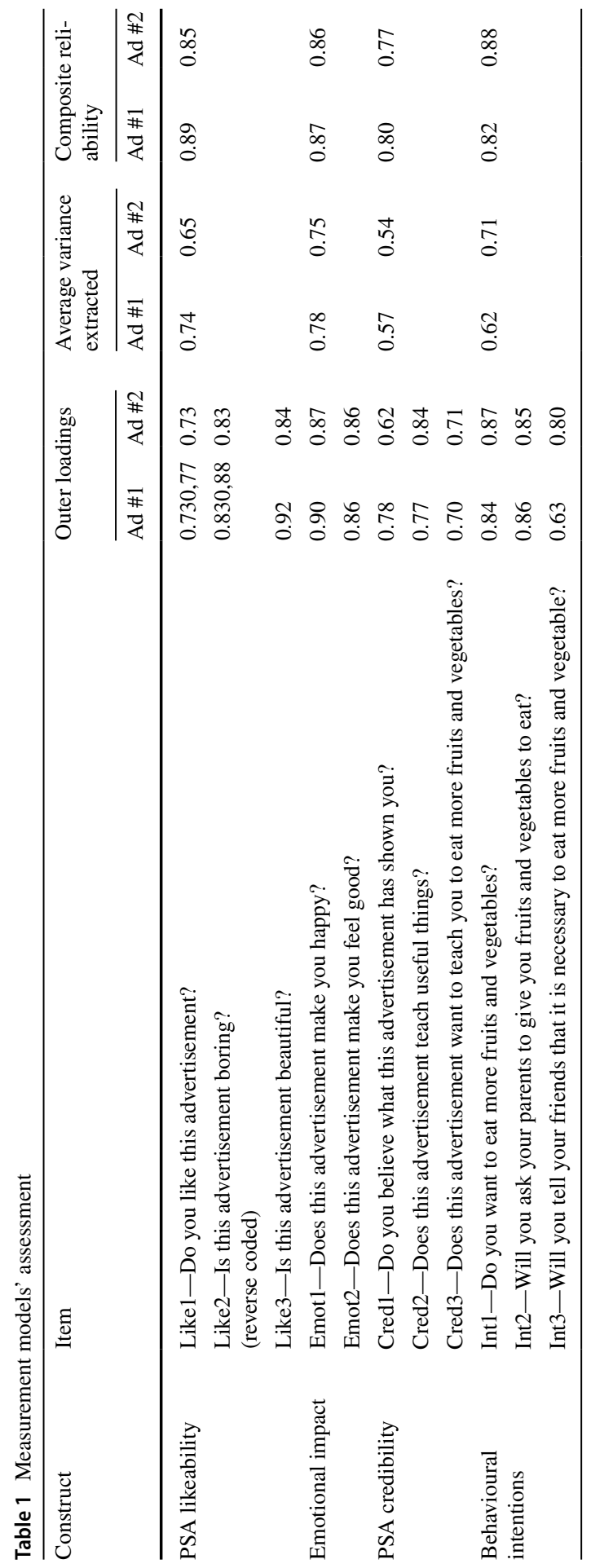


Table 2 Discriminant validity: correlations and square root values of the AVEs

\begin{tabular}{|c|c|c|c|c|c|c|c|c|}
\hline \multirow[t]{2}{*}{ Construct } & \multicolumn{4}{|l|}{ Ad \#1 } & \multicolumn{4}{|l|}{ Ad \#2 } \\
\hline & 1 & 2 & 3 & 4 & 1 & 2 & 3 & 4 \\
\hline 1. Behavioural intention & 0.789 & & & & 0.846 & & & \\
\hline 2. PSA Likeability & 0.240 & 0.862 & & & 0.047 & 0.809 & & \\
\hline 3. PSA credibility & 0.344 & 0.367 & 0.756 & & 0.543 & 0.173 & 0.736 & \\
\hline 4. Positive emotions & 0.288 & 0.606 & 0.429 & 0.885 & 0.277 & 0.536 & 0.269 & 0.870 \\
\hline
\end{tabular}

${ }^{*}$ The diagonal elements (in bold) are the square root values of the AVEs; off-diagonal elements are the correlation among constructs

0.85 (Henseler et al., 2015). It should also be considered that when the constructs cover concepts that are very similar to each other, HTMT values up to 0.90 can be acceptable (Hair et al., 2020). However, the highest value in our study was 0.797 (Table 3). Therefore, both Fornell-Larcker criterion and the HTMT ratio proved discriminant validity.

Before assessing the structural model, multigroup SEM analysis requires that measurement invariance is ensured, which guarantees that differences in the estimations across groups are not the result of different meanings of the latent variables across groups (Henseler et al., 2016). The measurement invariance of composite models (MICOM) procedure was used for this purpose (Hair et al., 2018). The first step of the MICOM procedure involves the assessment of the configural invariance. As identical indicators were used for the two groups, as well as data were treated similarly, configural invariance was established (Henseler et al., 2016). The second step of the MICOM procedure aims to assess compositional invariance. As shown in Table 4, the permutation test confirmed that all correlations among the constructs scores were always higher than the five-percent quantile of the distribution of the correlations resulting from 5,000 permutations (Henseler et al., 2016). As a result, partial measurement invariance was reached and path coefficients could be compared across groups through the multigroup analysis (Hair et al., 2018).

The findings obtained using the bootstrapping procedure (5,000 samples) are shown in Table 5 and in Fig. 2 (ad\#1) and Fig. 3 (ad \#2). Before analysing the structural paths, we checked the absence of collinearity issues by examining the Variance Inflation Factor (VIF) for each set of predictor constructs in each subpart of

Table 3 Discriminant validity: HTMT values

\begin{tabular}{|c|c|c|c|c|c|c|c|c|}
\hline \multirow[t]{2}{*}{ Construct } & \multicolumn{4}{|l|}{ Ad \#1 } & \multicolumn{4}{|l|}{ Ad \#2 } \\
\hline & 1 & 2 & 3 & 4 & 1 & 2 & 3 & 4 \\
\hline \multicolumn{9}{|c|}{ 1. Behavioural intention } \\
\hline 2. PSA Likeability & 0.274 & & & & 0.131 & & & \\
\hline 3. PSA credibility & 0.497 & 0.514 & & & 0.797 & 0.321 & & \\
\hline 4. Positive emotions & 0.407 & 0.743 & 0.638 & & 0.371 & 0.736 & 0.44 & \\
\hline
\end{tabular}


Table 4 Compositional invariance

\begin{tabular}{lllll}
\hline Construct & $\begin{array}{l}\text { Original correla- } \\
\text { tion }\end{array}$ & $\begin{array}{l}\text { Correlation permuta- } \\
\text { tion mean }\end{array}$ & $5.0 \%$ & $\begin{array}{l}\text { Permutation } \\
\text { p-values }\end{array}$ \\
\hline Behavioural intention & 0.999 & 0.985 & 0.951 & 0.954 \\
PSA Likeability & 0.999 & 0.994 & 0.980 & 0.839 \\
PSA credibility & 0.998 & 0.971 & 0.907 & 0.932 \\
Positive emotions & 1.000 & 0.996 & 0.986 & 0.771 \\
\hline
\end{tabular}

the model (Hair et al., 2020). The highest VIF values was 1.156 for ad\#1 and 1.031 for ad\#2, well below the maximum acceptable value of 5. The PLS-SEM structural model results confirmed that, for both groups, children's perceived likeability of PSAs had a positive effect on the emotional response to PSAs $(\beta=0.606, p<0.01$ and $\beta=0.563<p 0.01 ; \mathrm{H} 1$ is supported), which, in turn, had a positive effect on the perceived credibility of PSAs $(\beta=0.429, p<0.01$ and $\beta=0.269, p<0.01$; $\mathrm{H} 2$ is supported) that in turn, had a positive effect on children's behavioural intention to eat fruits and vegetables $(\beta=0.295, p<0.10$ and $\beta=0.551, p<0.01 ; \mathrm{H} 3$ is supported). However, children's perceived likeability of PSAs had no significant direct effect on their behavioural intention to eat fruits and vegetables $(\beta=0.131, p>0.10$ and $\beta=-0.049, p>0.10 ; \mathrm{H} 4$ is rejected). In addition, no significant effect of the control variable, i.e. age, was found. Finally, we applied a permutation test to ensure that the path coefficients were not statistically different between the two groups (Hair et al., 2020). The results of this analysis (Table 6) confirmed that the all structural relationships did not differ between the two groups, thus providing further evidence of the strength of the findings.

\section{Discussion}

\subsection{Theoretical implications}

The perceived likeability of PSAs or attitude toward PSAs is an important factor to consider when the effectiveness of social advertisements on children is analysed. The results showed that PSA likeability had an indirect effect (through the emotional reaction and the perceived credibility) on children's behavioural intention to eat fruits and vegetables, but there wasn't a significant direct effect between children's PSA likeability and their intention to consume healthy food.

As regards the direct effect, evidence indicates that children's positive attitudes toward commercial advertisements (or advertising likeability) have a direct influence on their purchase intention (D'Alessio et al., 2009; Pecheux \& Derbaix, 2002; Phelps \& Hoy, 1996). In contrast, this study found that the direct relationship between attitude toward PSA and behavioural intentions is questionable in the context of social advertisements. Hota et al. (2010) confirmed the same result in their study about PSAs aimed to children. They underlined the absence of a significant 


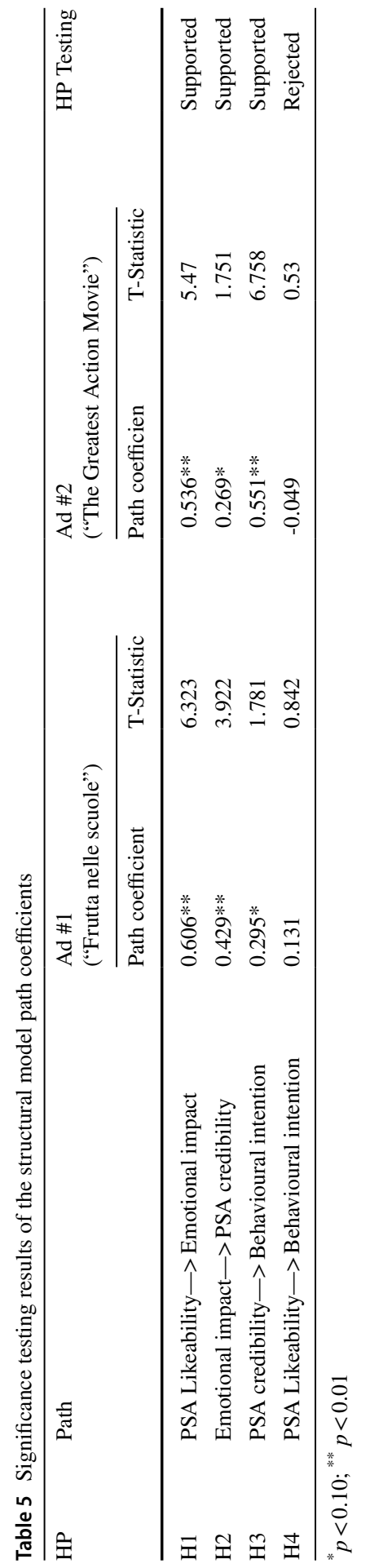




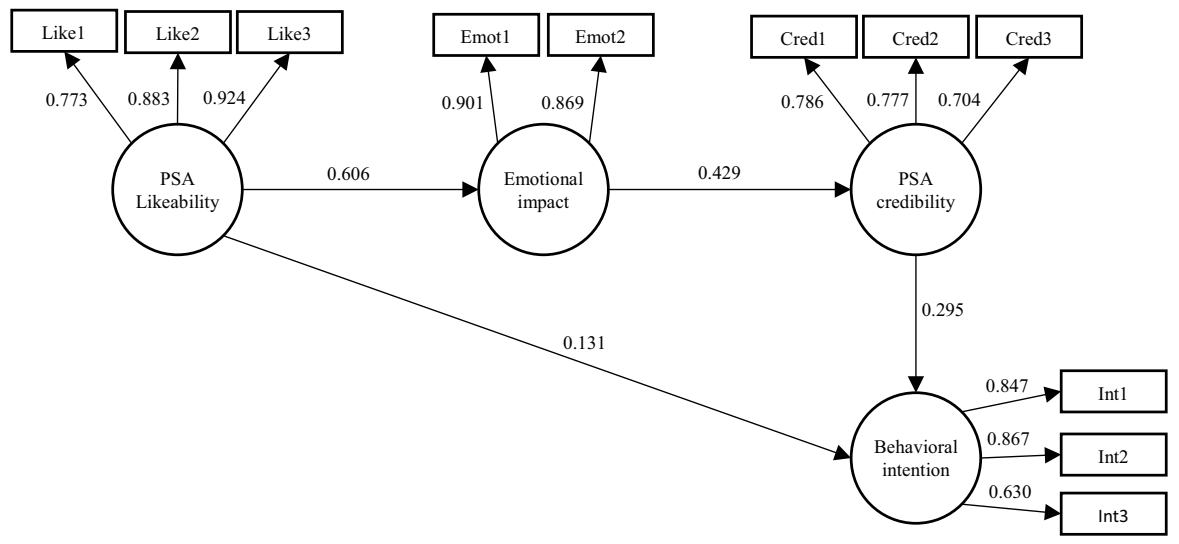

Fig. 2 PLS-SEM estimates for Ad \#1 ("Frutta nelle scuole")

direct effect between children's attitude toward an animated fruit PSA and the choice to consume fruits.

Smit et al. (2006) noted that some researchers think that advertisement likeability can be explained only as an affective response, but our findings confirm the idea that the combination of affective and cognitive elements has a real effect on behavioural intentions. Thus, it is interesting to note that positive emotions generated by PSAs permitted children to think about and believe in the content of social advertisements, and this in turn, influenced their intention to eat more fruits and vegetables.

According to Derbaix and Bree (1997), children's first response to advertisements is an emotional response. Therefore, whether children like a PSA, they express positive emotions. In addition, these authors argued that children's elaboration of the message seems low because children evaluate the executional elements of advertisements, rather than the elements related to the argument. By contrast, in this study we found that the processing of the message and its evaluation (measured through the perceived credibility of PSAs) had an important effect on the children's decision to

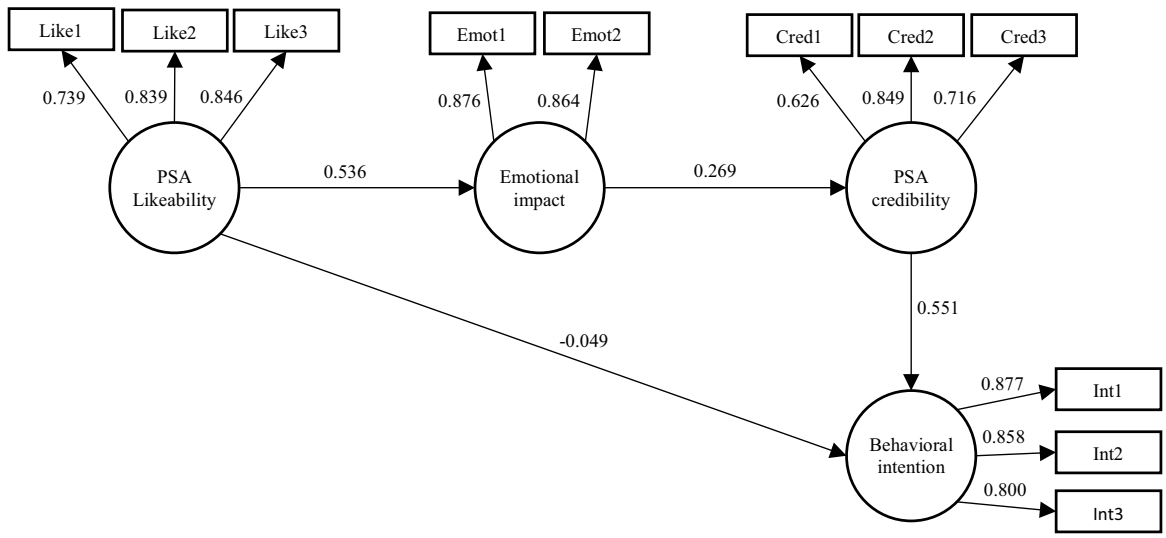

Fig. 3 PLS-SEM estimates for Ad \#2 ("The Greatest Action Movie Ever”) 


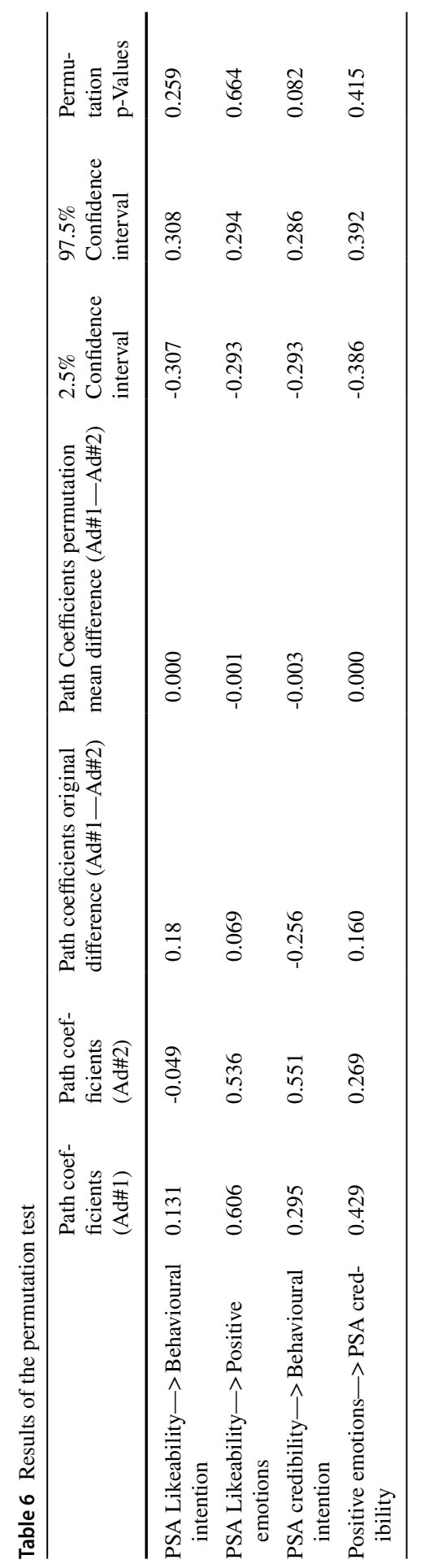


try to eat healthy food. Consequently, it may be useful to conduct further research on children's affective and cognitive responses simultaneously and the manner in which these two factors influence each other.

As previously mentioned, many studies (Boyland et al., 2012; Buijzen \& Valkenburg, 2002; Lawlor, 2009; Hebden et al., 2011; Page \& Brewster, 2007; Rose et al., 2012) have focused on children's affective response to commercials, identifying which aspects related to enjoyment and entertainment children prefer. Conversely, few studies measured children's judgments about the credibility of advertisements (Chan \& McNeal, 2004), and in particular, the concept of perceived message credibility is not applied to PSAs aimed at children.

Given the lack of research about the effectiveness of PSAs targeting children, our findings can be a starting point for further studies examining which factors influence children's healthy choice.

\subsection{Practical implications}

Few studies on PSAs try to understand the process that permits to influence children positively. Moreover, we cannot know the ways in which PSAs can increase good practices among children if we do not examine every factor and the relationship between factors in the process. Understanding the connections between PSA likeability, positive emotions, PSA credibility and behavioural intentions can facilitate the development of further social advertisements aimed at children covering other social themes. Therefore, the findings of this study are relevant for non-profit organizations, government institutions and advertisers interested in creating effective social marketing interventions (Baptista et al., 2020).

Social advertisements promoting healthy ways of life need to elicit positive emotions in children because in the positive affective state, they evaluate the message more positively. The positive evaluation of the message permits children to believe in the content of PSAs, and in turn, they are willing to change and improve their behaviour. For example, in their responses to this study's questionnaire, children not only state they intend to eat more fruits and vegetables, but also affirm that they will suggest to their friends that they should consume more healthy food. Therefore, it can be useful to use elements related to enjoyment and entertainment in PSAs for children to elicit positive emotions.

Despite this finding, it is important to be cautious in the use of entertainment elements such as fantasy because another aspect to consider is the cognitive response of children. The results showed that children's judgments about the credibility of advertisements have a direct effect on their behavioural intention. Only when they believe in the message, they can be persuaded. This means that emotional elements should be integrated with credible elements and rational explanations of the message. The two PSAs watched by children in the study used credible elements such as other children eating fruits and vegetables and arguments related to school. All this represents items familiar to children and as Peracchio and Luna (1998) stated, children often use analogical reasoning by drawing a parallel between what they see in advertisements and their real life. 


\subsection{Limitations and future research}

Several limitations should be considered when interpreting and generalizing these results. First, data were collected from a sample of Italian children aged 8 to 11 years. Future studies should evaluate whether these findings apply to children of other countries and to different age groups. Second, the children watched two PSAs that elicited positive emotions, but we do not know if negative emotions can have the same positive effect on the perceived PSA credibility. Therefore, future research should try to use moderate fear appeals. Moreover, the selection itself of the two PSAs may be a source of concern and may have had an influence on the outcomes. In fact, while the two PSAs were chosen based on the different levels of cognitive efforts required to process them, the effects of other differences between them were not explored. Potential concerns encompass differences in the main characters (personified fruits and vegetables vs. a group of real children) and in the distinct arguments (analogical reasoning vs. fantasy) to pursue the persuasive intent to make children eat fruits and vegetables. Moreover, the research design did not allow to manipulate credibility and likeability. Future research may conduct a true experiment, manipulating four conditions (credible/ incredible and likeable/unlikeable ads) to draw stronger conclusions about the determinants of behavioural intentions. In addition, further studies should also include variables associated to the message contents (for example nutritional knowledge) that were not considered in this research. Moreover, this study only analysed PSAs that promoted eating fruits and vegetables. Future studies should examine different types of PSAs targeting children. Finally, it would be interesting to address this research topic by adopting other techniques such as neuromarketing.

Funding Open access funding provided by Università degli Studi di Verona within the CRUI-CARE Agreement.

Open Access This article is licensed under a Creative Commons Attribution 4.0 International License, which permits use, sharing, adaptation, distribution and reproduction in any medium or format, as long as you give appropriate credit to the original author(s) and the source, provide a link to the Creative Commons licence, and indicate if changes were made. The images or other third party material in this article are included in the article's Creative Commons licence, unless indicated otherwise in a credit line to the material. If material is not included in the article's Creative Commons licence and your intended use is not permitted by statutory regulation or exceeds the permitted use, you will need to obtain permission directly from the copyright holder. To view a copy of this licence, visit http://creativecommons.org/ licenses/by/4.0/.

\section{References}

An, S., Jin, H. S., \& Park, E. H. (2014). Children's advertising literacy for advergames: Perception of the game as advertising. Journal of Advertising, 43(1), 63-72.

Appelman, A., \& Sundar, S. S. (2016). Measuring message credibility: Construction and validation of an exclusive scale. Journalism \& Mass Communication Quarterly, 93(1), 59-79.

Ardizzone, A., Faralla, V., \& Novarese, M. (2019). Children's organic fruit nectar satisfaction: an experimental economics approach. British Food Journal, 121(4), 856-873. 
Atkin, C. K., \& Rice, R. E. (2013). Advances in public communication campaigns. In E. Scharrer (Ed.), The International Encyclopedia of Media Studies (pp. 526-551). Wiley-Blackwell.

Bagnato, C., Blangiardo, G.C., Bologna, E., Burgio, A., Busetto, L., Caretto, A., Carruba, M., Cianfarani, S., Crisalesi, R., Cricelli, C., D’Angela, D., Di Lorenzo, N., Fatati, G., Fochi, D., Gargiulo, L., Gaudioso, A. \& Giordani, C. (2020). Obesity Monitor. Monitoring prevention, cure, political, social and economic facts on obesity care. Available at https://viewer.ipaper.io/sp-servizi-pubblicitari-srl/obesity-barometermonitor/ (Accessed 3 December 2020).

Bagozzi, R. P., Gopinath, M., \& Nyer, P. U. (1999). The role of emotions in marketing. Journal of the Academy of Marketing Science, 27(2), 184-206.

Baptista, N., Alves, H., \& Pinho, J. C. (2020). Uncovering the Use of the Social Support Concept in Social Marketing Interventions for Health. Journal of Nonprofit \& Public Sector Marketing, 1-35.

Batada, A., \& Wootan, M. G. (2007). Nickelodeon markets nutrition-poor foods to children. American Journal of Preventive Medicine, 33(1), 48-50.

Baumgartner, E., \& Laghi, F. (2012). Affective responses to movie posters: Differences between adolescents and young adults. International Journal of Psychology, 47(2), 154-160.

Blades, M., Oates, C., \& Li, S. (2013). Children's recognition of advertisements on television and on Web pages. Appetite, 62, 190-193.

Boyland, E. J., \& Halford, J. C. (2013). Television advertising and branding. Effects on eating behaviour and food preferences in children. Appetite, 62, 236-241.

Boyland, E. J., Harrold, J. A., Kirkham, T. C., \& Halford, J. C. (2012). Persuasive techniques used in television advertisements to market foods to UK children. Appetite, 58(2), 658-664.

Buijzen, M., Schuurman, J., \& Bomhof, E. (2008). Associations between children's television advertising exposure and their food consumption patterns: A household diary-survey study. Appetite, 50(2-3), 231-239.

Buijzen, M., \& Valkenburg, P. M. (2002). Appeals in television advertising: A content analysis of commercials aimed at children and teenagers. Communications, 27(3), 349-364.

Buijzen, M., \& Valkenburg, P. M. (2003). The effects of television advertising on materialism, parentchild conflict, and unhappiness: A review of research. Journal of Applied Developmental Psychology, 24(4), 437-456.

Cairns, G., Angus, K., Hastings, G., \& Caraher, M. (2013). Systematic reviews of the evidence of the nature, extent and effects of food marketing to children. A Retrospective Summary, Appetite, 62, 209-215.

Carter, O. B., Patterson, L. J., Donovan, R. J., Ewing, M. T., \& Roberts, C. M. (2011). Children's understanding of the selling versus persuasive intent of junk food advertising: Implications for regulation. Social Science \& Medicine, 72(6), 962-968.

Castonguay, J., McKinley, C., \& Kunkel, D. (2013). Health-related messages in food advertisements targeting children. Health Education, 113(5), 420-432.

Center for Disease Control and Prevention (2017). Childhood Obesity Facts. Available at: https://www. cdc.gov/healthyschools/obesity/facts.htm (Accessed 12 March 2018).

Chan, K. (2000). Hong Kong children's understanding of television advertising. Journal of Marketing Communications, 6(1), 37-52.

Chan, K. (2001). Children's perceived truthfulness of television advertising and parental influence: A Hong Kong study. Advances in Consumer Research, 28, 207-212.

Chan, K. (2014). Advertising to children in China. In M. Blades (Ed.), Advertising to Children (pp. 93-114). Palgrave Macmillan.

Chan, K., \& McNeal, J. U. (2002). Children's perceptions of television advertising in urban China. Young Consumers: Insight and Ideas for Responsible Marketers, 3(3), 69-79.

Chan, K., \& McNeal, J. U. (2004). Chinese children's attitudes towards television advertising: truthfulness and liking. International Journal of Advertising, 23(3), 337-359.

Chan, K., \& Zhang, T. (2019). An exploratory study on perception of celebrity endorsement in public services advertising. International Review on Public and Nonprofit Marketing, 16(2-4), 195-209.

Charry, K. M. (2014). Product placement and the promotion of healthy food to pre-adolescents: When popular TV series make carrots look cool. International Journal of Advertising: the Quarterly Review of Marketing Communications, 33(3), 599-616.

D’Alessio, M., Laghi, F., \& Baiocco, R. (2009). Attitudes toward TV advertising: A measure for children. Journal of Applied Developmental Psychology, 30(4), 409-418. 
Derbaix, C., \& Bree, J. (1997). The impact of children's affective reactions elicited by commercials on attitudes toward the advertisement and the brand. International Journal of Research in Marketing, 14(3), 207-229.

Derbaix, C., \& Pecheux, C. (2003). A new scale to assess children's attitude toward TV advertising. Journal of Advertising Research, 43(4), 390-399.

Dixon, H., Niven, P., Scully, M., \& Wakefield, M. (2017). Food marketing with movie character toys: Effects on young children's preferences for unhealthy and healthier fast food meals. Appetite, 117, 342-350.

Eagly, A. H., \& Chaiken, S. (2007). The advantages of an inclusive definition of attitude. Social Cognition, 25(5), 582-602.

Ebster, C., Wagner, U., \& Neumueller, D. (2009). Children's influences on in-store purchases. Journal of Retailing and Consumer Services, 16(2), 145-154.

Eck, K. M., Delaney, C., Olfert, M. D., Hagedorn, R. L., Leary, M. P., Santella, M. E., et al. (2019). Parents' and kids' eating away from home cognitions. British Food Journal, 121(5), 582-602.

Erevelles, S. (1998). The role of affect in marketing. Journal of Business Research, 42(3), 199-215.

European Commission. (2014). EU Action Plan on Childhood Obesity 2014-2020. Available at: https:// ec.europa.eu/health/sites/health/files/nutrition_physical_activity/docs/childhoodobesity_actionplan_ 2014_2020_en.pdf (Accessed 12 March 2018).

Ferguson, C. J., Muñoz, M. E., \& Medrano, M. R. (2012). Advertising influences on young children's food choices and parental influence. The Journal of Pediatrics, 160(3), 452-455.

Folkvord, F., Roes, E., \& Bevelander, K. (2020). Promoting healthy foods in the new digital era on Instagram: an experimental study on the effect of a popular real versus fictitious fit influencer on brand attitude and purchase intentions. BMC Public Health, 20, 1677.

Fornell, C., \& Larcker, D. F. (1981). Evaluating structural equation models with unobservable variables and measurement error. Journal of Marketing Research, 18(1), 39-50.

Freeman, D., \& Shapiro, S. (2014). Tweens' Knowledge of Marketing Tactics: Skeptical Beyond Their Years. Journal of Advertising Research, 54(1), 44-55.

Gantz, W., Schwartz, N., Angelini, J. R., \& Rideout, V. (2008). Shouting to be heard: public service advertising in a changing television world. Available at: https://kaiserfamilyfoundation.files.wordpress. com/2013/01/7715.pdf (Accessed 12 March 2018).

Ghani, N. H. A., \& Zain, O. M. (2004). Malaysian children? s attitudes towards television advertising. Young Consumers: Insight and Ideas for Responsible Marketers, 5(3), 41-51.

Goldsmith, R. E., Lafferty, B. A., \& Newell, S. J. (2000). The impact of corporate credibility and celebrity credibility on consumer reaction to advertisements and brands. Journal of Advertising, 29(3), 43-54.

Gulla, A., \& Purohit, H. (2013). Children's attitude towards television advertisements and influence on the buying behavior of parents. International Journal of Marketing, Financial Services, 2(6), 103-117.

Hair, J. F., Hult, G. T. M., Ringle, C. M., \& Sarstedt, M. (2017). A Primer on Partial Least Squares Structural Equation Modeling (PLS-SEM) (2ed.). Thousand Oaks, CA: Sage.

Hair, J. F., Risher, J. J., Sarstedt, M., \& Ringle, C. M. (2019). When to use and how to report the results of PLS-SEM. European Business Review, 31(2), 2-24.

Hair, J. F., Sarstedt, M., Ringle, C. M., \& Gudergan, S. P. (2018). Advanced Issues in Partial Least Squares Structural Equation Modeling. SAGE Publications.

Hair, J. F., Hult, T. M., Ringle, C., Sarstedt, M., Magno, F., Cassia, F., \& Scafarto, F. (2020). Le equazioni strutturali Partial Least Squares. Introduzione alla PLS-SEM. FrancoAngeli.

Hampson, S. E., Martin, J., Jorgensen, J., \& Barker, M. (2009). A Social Marketing Approach to Improving the Nutrition of Low-Income Women and Children: An Initial Focus Group Study. Public Health Nutrition, 12, 1563-1568.

Hebden, L., King, L., \& Kelly, B. (2011). Art of persuasion: an analysis of techniques used to market foods to children. Journal of Paediatrics and Child Health, 47(11), 776-782.

Henseler, J., Ringle, C. M., \& Sarstedt, M. (2015). A New Criterion for Assessing Discriminant Validity in Variance-based Structural Equation Modeling. Journal of the Academy of Marketing Science, 43(1), 115-135. https://doi.org/10.1007/s11747-014-0403-8

Henseler, J., Ringle, C. M., \& Sarstedt, M. (2016). Testing Measurement Invariance of Composites Using Partial Least Squares. International Marketing Review, 33(3), 405-431.

Hingle, M., \& Kunkel, D. (2012). Childhood obesity and the media. Pediatric Clinics, 59(3), 677-692. 
Hota, M., Cáceres, R. C., \& Cousin, A. (2010). Can Public-Service Advertising Change Children's Nutrition Habits?: The Impact of Relevance and Familiarity. Journal of Advertising Research, 50(4), $460-477$.

Istituto Superiore della Sanità, Epicentro. (2020). All'ISS il nuovo Centro di collaborazione dell'OMS per l'obesità infantile. Available at https://www.epicentro.iss.it/obesita/iss-collaborating-centeroms (Accessed 3 December 2020).

Jenkin, G., Madhvani, N., Signal, L., \& Bowers, S. (2014). A systematic review of persuasive marketing techniques to promote food to children on television. Obesity Reviews, 15(4), 281-293.

Kelly, B., Hattersley, L., King, L., \& Flood, V. (2008). Persuasive food marketing to children: use of cartoons and competitions in Australian commercial television advertisements. Health Promotion International, 23(4), 337-344.

Kim, H., Lee, D., Hong, Y., Ahn, J., \& Lee, K. Y. (2016). A content analysis of television food advertising to children: Comparing low and general-nutrition food. International Journal of Consumer Studies, 40(2), 201-210.

Kim, M., \& Cappella, J. N. (2019). Reliable, valid and efficient evaluation of media messages. Journal of Communication Management, 23(3), 179-197.

Kubacki, K., Rundle-Thiele, S., Lahtinen, V., \& Parkinson, J. (2015). A systematic review assessing the extent of social marketing principle use in interventions targeting children (2000-2014). Young Consumers, 16(2), 141-158.

Lafferty, B. A., Goldsmith, R. E., \& Newell, S. J. (2002). The dual credibility model: The influence of corporate and endorser credibility on attitudes and purchase intentions. Journal of Marketing Theory and Practice, 10(3), 1-11.

Lawlor, M.-A. (2009). Advertising connoisseurs: Children's active engagement with and enjoyment of television advertising. Irish Marketing Review, 20(1), 23-34.

Leather, P., McKechnie, S., \& Amirkhanian, M. (1994). The importance of likeability as a measure of television advertising effectiveness. International Journal of Advertising, 13(3), 265-280.

Lencucha, R., Dubé, L., Blouin, C., Hennis, A., Pardon, M., \& Drager, N. (2018). Fostering the Catalyst Role of Government in Advancing Healthy Food Environments. International Journal of Health Policy and Management, 7(6), 485-490.

Lioutas, E., \& Tzimitra-Kalogianni, I. (2015). 'I saw Santa drinking soda!' Advertising and children's food preferences. Child: care, health and development, 41(3), 424-433.

Lobstein, T., Baur, L., \& Uauy, R. (2004). Obesity in children and young people: a crisis in public health. Obesity Reviews, 5, 4-85.

MacKenzie, S. B., \& Lutz, R. J. (1989). An empirical examination of the structural antecedents of attitude toward the ad in an advertising pretesting context. Journal of Marketing, 53(2), 48-65.

Mulligan, K., \& Scherer, K. R. (2012). Toward a working definition of emotion. Emotion Review, 4(4), 345-357.

National Collaborative on Childhood Obesity Research. (2011). Annual Report. Available at: http://www. nccor.org/wp-content/uploads/2016/09/NCCOR_2011AnnualReport.pdf (Accessed 12 March 2018).

Nicolini, V., Cassia, F., \& Bellotto, M. (2017). Children perceptions of emotional and rational appeals in social advertisements. Young Consumers, 18(3), 261-277. https://doi.org/10.1108/YC-02-2017-00665

Oates, C., Blades, M., \& Gunter, B. (2002). Children and television advertising: When do they understand persuasive intent? Journal of Consumer Behaviour: an International Research Review, 1(3), 238-245.

Obermiller, C., \& Spangenberg, E. R. (1998). Development of a scale to measure consumer skepticism toward advertising. Journal of Consumer Psychology, 7(2), 159-186.

Ogden, C. L., Carroll, M. D., Fryar, C. D., \& Flegal, K. M. (2015). Prevalence of obesity among adults and youth: United States, 2011-2014. Available at: https://www.cdc.gov/nchs/data/databriefs/ db219.pdf (Accessed 12 March 2018).

Ohanian, R. (1991). The impact of celebrity spokespersons' perceived image on consumers' intention to purchase. Journal of Advertising Research, 31(1), 46-54.

Page, B., Sharp, A., Lockshin, L., \& Sorensen, H. (2018). Parents and children in supermarkets: Incidence and influence. Journal of Retailing and Consumer Services, 40, 31-39.

Page, R. M., \& Brewster, A. (2007). Emotional and rational product appeals in televised food advertisements for children: analysis of commercials shown on US broadcast networks. Journal of Child Health Care, 11(4), 323-340.

Pecheux, C., \& Derbaix, C. (1999). Children and attitude toward the brand: A new measurement scale. Journal of Advertising Research, 39(4), 19-19. 
Pecheux, C., \& Derbaix, C. (2002). Children's reactions to advertising communication: multiple methods, moderating variables and construct validity issues. Advances in Consumer Research, 29, 531-538.

Peracchio, L. A., \& Luna, D. (1998). The development of an advertising campaign to discourage smoking initiation among children and youth. Journal of Advertising, 27(3), 49-56.

Persson M, Soroko R, Musicus A, \& Lobstein T. (2012). A junk-free childhood 2012: the 2012 report of the StanMark project on standards for marketing food and beverages to children in Europe: a briefing paper from the International Association for the Study of Obesity. 2012. Available at https://s3. eu-central-1.amazonaws.com/ps-wof-web-dev/site_media/uploads/IASO_food_marketing_report_ 30_June_2011.pdf. (Accessed 1 December 2020).

Pettigrew, S., \& Pescud, M. (2012). Improving parents' child-feeding practices: a social marketing challenge. Journal of Social Marketing, 2(1), 8-22.

Pettigrew, S., Tarabashkina, L., Roberts, M., Quester, P., Chapman, K., \& Miller, C. (2013). The effects of television and Internet food advertising on parents and children. Public Health Nutrition, 16(12), 2205-2212.

Petty, R. E., Cacioppo, J. T., \& Schumann, D. (1983). Central and peripheral routes to advertising effectiveness: The moderating role of involvement. Journal of Consumer Research, 10(2), 135-146.

Phelps, J. E., \& Hoy, M. G. (1996). The Aad-Ab-PI relationship in children: The impact of brand familiarity and measurement timing. Psychology \& Marketing, 13(1), 77-105.

Porter, M. C., Anderson, B., \& Nhotsavang, M. (2015). Anti-social media: executive Twitter "engagement" and attitudes about media credibility. Journal of Communication Management, 19(3), 270-287.

Priya, P., Baisya, R. K., \& Sharma, S. (2010). Television advertisements and children's buying behaviour. Marketing Intelligence \& Planning, 28(2), 151-169.

Puggelli, F. R., \& Bertolotti, M. (2014). Healthy and unhealthy food in Italian television ads for adults and children. Young Consumers, 15(1), 58-67.

Raine, K. D. (2005). Determinants of healthy eating in Canada: an overview and synthesis. Canadian Journal of Public Health/Revue Canadienne De Sante'e Publique, S8-S14.

Ringle, C. M., Wende, S., \& Becker, J.-M. (2015). SmartPLS 3. Bönningstedt: SmartPLS.

Roozen, I. (2013). The impact of emotional appeal and the media context on the effectiveness of commercials for not-for-profit and for-profit brands. Journal of Marketing Communications, 19(3), 198-214.

Rose, G. M., Merchant, A., \& Bakir, A. (2012). Fantasy in food advertising targeted at children. Journal of Advertising, 41(3), 75-90.

Rossiter, J. R. (1979). Does TV advertising affect children? Journal of Advertising Research, 19, 39-45.

Ruiz, S., Sicilia, M. (2004). The impact of cognitive and/or affective processing styles on consumer response to advertising appeals. Journal of Business Research, 57(6), 657-664.

Smit, E. G., Van Meurs, L., \& Neijens, P. C. (2006). Effects of advertising likeability: A 10-year perspective. Journal of Advertising Research, 46(1), 73-83.

Soh, H., Reid, L. N., \& King, K. W. (2009). Measuring trust in advertising. Journal of Advertising, 38(2), 83-104.

Thakor, M. V., \& Goneau-Lessard, K. (2009). Development of a scale to measure skepticism of social advertising among adolescents. Journal of Business Research, 62(12), 1342-1349.

Valkenburg, P. M. (2004). Children's responses to the screen: A media psychological approach. Routledge.

Valkenburg, P. M., \& Buijzen, M. (2005). Identifying determinants of young children's brand awareness: Television, parents, and peers. Journal of Applied Developmental Psychology, 26(4), 456-468.

Verma, I. (2014). Advertising credibility: a review of literature. International Interdisciplinary Research Journal, 2(1), 189-199.

WHO. (2016). Final report of the Commission on ending childhood obesity. Available at: www.who.int/ dietphysicalactivity/childhood/en/ (Accessed 12 March 2018).

Xie, H., Minton, E. A., \& Kahle, L. R. (2016). Cake or fruit? Influencing healthy food choice through the interaction of automatic and instructed mental simulation. Marketing Letters, 27, 627-644.

Yoo, C., \& MacInnis, D. (2005). The brand attitude formation process of emotional and informational ads. Journal of Business Research, 58(10), 1397-1406.

Publisher's Note Springer Nature remains neutral with regard to jurisdictional claims in published maps and institutional affiliations. 